\title{
Ethics and law in the field of medical care for the elderly in France
}

\author{
Sophie Gromb, the late Gerard Manciet and Arnaud Descamps Bordeaux University Hospital, Bordeaux \\ Teaching Hospital and Xavier Arnozan \\ Hospital, Pessac, France
}

\begin{abstract}
The authors discuss law and ethics when medical decisions are to be taken by patients who are unable in any valid sense to express their own wishes. The main problem in legal terms is to protect an individual's free will as far as possible and ensure that his or her wishes, if known, are respected. If a patient's independent wishes cannot be known, then we must at least ensure that nothing is imposed which is not in his interest. Legal measures, however, are far from adequate in resolving all the concrete problems that emerge. The field of ethics does bring some better adapted solutions, but none is laid down in law. One such approach, involving a multidisciplinary advisory group in a department of geriatrics, is discussed.
\end{abstract}

\section{Résumé}

Les auteurs étudient l'apport du droit et de l'éthique lors de prises de décisions médicales chez des personnes qui ne peuvent pas valablement indiquer ce qu'elles désirent. Le principal probleme pour le droit est de protéger le libre arbitre de la personne et de veiller à ce que sa volonté soit respectée. Mais l'arsenal législatif est loin de résoudre les problèmes concrets qui se posent. L'éthique apporte certes des solutions plus adaptées mais aucune n'est préetablie.

The distinction between ethics and legality in relation to care for the elderly is a most complex problem which we cannot hope to deal with fully in this paper. However, for clarification, we shall first give the standard definition of each of these two sets of rules before presenting our thoughts on the two aspects of the question.

The first point to be made is that the rule of law is inequivocably impersonal, general and abstract. Its main characteristic is that it is accompanied by some form of civil or criminal sanction, imposed by the state.

Thus, the law is essentially impartial, whereas the ethical questions are more subjective, rules of moral conduct, handed down by our forebears, which are,

\section{Key words}

Elderly; consent; protection of the incompetent; ethics. however, gradually becoming more secularised and pragmatic.

Regarding care of the elderly, the main legal problem is respect for a person's individual liberty, which will be dealt with in the first part of the paper; a discussion of ethics follows, focusing on instances where the question of ethics arises in treatment, based on an experiment at the Bordeaux University Hospital, which was begun in 1993.

\section{Law and individual liberty}

Since the French Revolution, the French have all been free citizens, and the elderly, no less than anyone else, enjoy their full legal rights and independence, in the strictly legal sense of the term. In other words, they may freely express their will and this expression has an effect. This is the basis of the notion that everyone is equal before the law.

This freedom, so dear to the hearts of contemporary society and jealously guarded by international bodies which uphold the rights of man, nevertheless has certain restrictions and limitations with respect to the fields of public interest, public order and public health. This is part of a different problem, however, that of public liberty.

In France, the constitution guarantees individual liberty and is equipped with a vast arsenal of legal measures with which to protect vulnerable individuals or those whose faculties may be in some way impaired.

The elderly benefit from this legal protection which, if the situation requires it, should be associated with consent to a medical act. ${ }^{1}$ We should first, perhaps, review the legal system in France as it relates to medical acts in general. ${ }^{2}$

THE LEGAL SYSTEM RELATING TO MEDICAL CARE Caring for the elderly is by no means a simple matter in legal terms, as it is necessary to arbitrate, often a difficult matter, between on the one hand, respecting their wishes and their freedom and on the other, our duty of care towards those who are powerless.

It may even be necessary on occasion to act against their will. 
The human body is protected by French law, which has at its disposal a battery of legal sanctions.

Certain forms of behaviour, deemed to be contrary to the rules which ensure social cohesion, are specifically described in the penal code : this is known as "incrimination". When an offender commits such acts, he will incur sanctions, which are also specified in the code.

\section{Two types of violation}

There are two types of violation against a person: voluntary and involuntary.

In theory, any violation of a person's physical integrity, no matter how slight, should give rise to criminal proceedings.

There are certain instances in French law, however, where such violations are deemed justifiable and sanctions are not applied, for example, selfdefence, necessity or legal authorisation.

The legal system authorises and organises medical activity. In particular, it allows the violation of a person's integrity, provided that this is for some medical purpose, and is in accordance with the patient's wishes.

This legal principle is of such importance that it has recently been written into law, in the vote on bioethical laws, 29 July 1994.

Article 16.3 of the code of civil law states that "No violation of the human body is allowed except when this is necessary in order to treat a person. The consent of the individual must be sought beforehand, unless his medical state is such that he is not in a position to give his consent to the medical treatment he requires".

There are two concepts which create major difficulties for doctors on a daily basis :

- the medical purpose of an act must be respected: this represents a limit to treatment which must not be crossed, with any violation condemned by penal law as assault and battery and even wilful homicide.

For example, the act of euthanasia, defined as a positive and deliberate act, committed with the intention of bringing about death, is an act of murder.

It is important to note in this respect that although patient consent is an indispensable condition for the carrying out of a medical act, it cannot render legal any action which the law forbids.

Criminal law is normative; its purpose is to protect and maintain public order and no individual can evade it, thus even if a murdered person consents to his own murder, this can in no way reduce the blame attached to the act, no matter how laudable the motive may be (pity, kindness, etc).

This is the basic principle, although courts sometimes show a degree of clemency.

The requirement for an action to have a medical purpose can, to an extent, be flexible. For example, in cases relating to biomedical research, or organ transplant, although the actions are not of direst beneflt to the person concerned, in the long ten they benefit the community as a whole.

For every exception to the rule, however, our legal system requires a debate and a vote in the nation assembly, with the outcome submitted to the scrutiny of the "conseil constitutionnel", the consitutional advisory committee.

- the patient's wishes must be respected. In France, there are two different legal contexts in whieh medical acts can be carried out: the private cæe sector and the public health sector.

In the former, jurisprudence states that the relationship between doctor and patient is a private laww contract. One condition for the existence and validity of such a contract is the consent of those concerned.

In the latter, the patient is a user of a public service. $\mathrm{He}$ has no (legal) relationship with the doctors, who are agents of the service, only with the administrative body.

This notwithstanding, the doctor must obtain the consent of the patient beforehand. This is not on an ethical or professional obligation (article 7 of ethical code), but it is also a legal and established duty, as defined in article 16.3 of the code of civil lasw (law of bioethics, 29 July 1994). When the padient consents to medical treatment, he must do so iefitl knowledge of the facts. This implies that the dgetwr must provide straightforward, honest and intelligigie information to the patient, who is assumed to haye no prior medical knowledge.

But how can the patient give his consent if he is incapable of expressing his wishes, and if he is not full possession of his decision-making, physical and mental faculties. It is here that the problems beg

The elderly whom we see in geriatric departments are usually dependants. Being a dependa however, is not synonymous with incompetency: ifis important not to lose sight of the fact that competency is the rule, incompetency the exception.

\section{Special legislation}

In order to protect adults who are "incompetent" the legal sense, ie who are over 18 (the age $\overline{\bar{\theta}} \mathrm{f}$ majority) but are unable to act independently. In their own interest because of some impairment their mental faculties, special legislation exists. This is the law of 3 January 1968, which states: "when tile mental faculties are impaired as a result of illness, disability or frailty due to age, a protection syste्gm takes care of the person's interests. . " .

This special legal protection is not accorded automatically but must be requested, and it is for t is reason that among the elderly population some \& protected and others not. There are three separise protection systems, depending on the extent to which the person is affected: a protection order, which is a partial or temporary measure; "curatelle", 
a form of guardianship to provide assistance, and "tutelle", guardianship to provide representation.

a) Those not covered by the protection system:

- either the individual is capable legitimately and effectively of giving his consent or expressing his will in a valid way, in which case his will must be respected, even if he refuses treatment;

- or his faculties are failing due to age and his legal representative (spouse, parents, descendants, brothers and sisters) or a person who has the role of "natural protector" (as defined by the supreme court) speaks on his behalf.

However, even though the course of action to be taken is clearly laid down in law, we know that in practice, there are conflicts of interest which make a consensus decision difficult.

In these difficult cases, or where there is no family, it is always possible to request that the attorney general place a protection order. This option derives from the fact that in the French legal system, the attorney general not only represents the interests of society and protects its values by demanding sanctions for wrongdoing, but is also the protector of individual liberties, and it is in this capacity that he is concerned in this type of problem.

\section{b) Those covered by the protection system:}

The main problem with the 3 January 1968 law setting up the various legal protection systems, is that it was not intended to protect a person as an individual; it was meant to protect a person's inheritance.

The three systems can be defined as follows :

Protection order: the protected person is not dispossessed of his civil rights, but any actions instigated during the period of protection which may be detrimental to the patient can be remedied at a later date; "Curatelle" guardianship: in this case the mental and bodily faculties have so deteriorated that the person is not in a fit state to act alone and needs advice and supervision in actions relating to his civil status. A guardian is appointed, preferably the spouse or someone from the person's circle of family and friends; otherwise state guardianship may be decided on and a registered body appointed ;

"Tutelle" guardianship: the person's faculties are so impaired that he is unable to express his own will and needs constant representation.

There are several types of "tutelle" guardianship: total guardianship: this is fairly complicated to implement, involving the appointed guardian, the board of guardians (relatives and close family) and the supervising judge; a simplified form of this guardianship consists of only the guardian (a close relative) and the supervising judge; if there is no appropriate family member, state guardianship may be declared, which consists of a registered guardianship body and the supervising judge; lastly, in cases where the inheritance is only small, an administered guardianship is declared: this usually involves the appointment of a representative from the nursing home as administrator, under the supervision of the judge.

Since 6 November 1974, it has been possible to appoint a guardian for a person, as distinct from a guardian for a person's property.

Following this, a ruling in the first civil chamber of the court of appeal, 18 April 1989, stated that "the objective of the incompetency rules are, generally speaking, to provide for the protection of the person and the property of the incompetent person".

Unfortunately, these different types of representation do not solve all problems: not only is the procedure for placing someone under guardianship a long and complex one, but, more especially, it provides little help when dealing with consent to medical treatment.

\section{CONSENT TO MEDICAL TREATMENT}

The definition of a medical act is treatment intended to be curative given to a person who is ill. This therefore differs from nursing or care in the home, which are not strictly speaking medical acts. The principle currently accepted by doctrine and by jurisprudence is that an individual has very wide autonomy.

It is well known that the capacity to act for oneself, even partially, can have healing properties and doctors believe that it is dangerous to suggest and to reinforce a state of dependency in a psychopath.Thus even though a person of age is protected by the law, as long as he is aware of his true condition, his guardian is providing only a forrn of assistance and arbitration rather than actual representation.

There is a distinction between a commonplace medical act (doctor's visit, consultation) and one which might seriously affect the patient's health or soundness of body.

The rule is: the patient must participate in the consent Whatever protection regime is adopted, and as long as the person is lucid, it is he who must give his consent to the medical act.

It is possible to give substitute consent on his behalf, but he must not have authority imposed on him like a child.

Even the guardian or the board of guardians cannot decide on treatment against the will of the patient, unless this is treatment which must be imposed in view of his state of health; for instance, when a patient is suffering from mental problems which make it impossible for him to give his consent, but it is imperative that he be hospitalised, either to receive treatment or to protect public order and safety (law of 27 June, 1990). Apart from this instance, the patient's consent is always required.

Article 43 of the code of medical ethics underlines the fact that even consent given in a short interval of 
lucidity șhould, wherever possible, be complied with.

In fact, in practice, the medical practitioner is given a very wide initiative in this matter.

If the person is an adult under "tutelle" guardianship, the guardian may take a (non-urgent) medical decision in relation to any necessary commonplace medical acts. For any medical act which might seriously affect an individual's health, authorisation is also needed from the board of guardians or from the supervising judge.

A guardian cannot force an adult, for example, to enter a treatment centre against his will; in order to do this he must apply to the judge.

If the adult is under a "curatelle" guardianship or a protection order, then the legal definition of competency is used. Thus the adult may be capable of giving his consent.

When under a guardianship, he can consent only to mundane acts; for other medical acts involving serious decisions, he must refer to the guardian or to the judge.

If the guardian refuses his help in the case of an extremely serious medical act, then the judge must provide supplementary authorisation (article 510, \$2).

If the judge also refuses, such a refusal can give rise to an appeal before the supreme court, which guarantees individual liberties.

When an adult is under a protection order, he may give his consent, alone, to all types of medical acts.

\section{The exception: total absence of consent}

This occurs when the mental faculties are seriously affected, and the individual has no will of his own. This eventuality should be avoided wherever possible.

In all events, the consent of the incompetent patient should be gained whenever he is physically able to give it.

Finally, to conclude this section on the law, it is always possible, in an acute emergency, to appeal to the attorney general for a decision.

\section{Ethical points on difficult decisions when recommending treatment}

It is in this area that the divide between law and ethics is at its widest. As we have already seen, even though our legal system provides solutions, these are not always simple to apply to the situations with which we are confronted (A). This problem has prompted us to set up an experiment which may help to provide new solutions (B).

\section{(A) DIFFICULTIES OF APPRECIATION}

What happens in reality?

In patients with functional and cognitive disorders their level of lucidity tends to fluctuate a great deal.
Where do we draw the line in such cases, what is the extent of their capacity to give consent?

We are justified in asking why we should go $\overrightarrow{\mathrm{IO}}$ such extreme lengths to obtain a protection measure, when we know that the supervising judges, the attorney general and, to an even greater extent, the board of guardians are loathe to come to a decision one way or another as they are in effect deciding a patient's comfort and life expectancy.

Legal experts, who can be quick to criticise "medical imperialism", are more than willing to shoft the responsibility of such decisions onto the carers. In the front line are the doctors, who would willingly be relieved of the weight of this almost superhuman burden.

Depressives can present a major problem. The्gुr self-destructive urges must be detected and they must then be protected from themselves. All care $\$$ have seen examples of patients who have wanted io "end it all " and yet who, several months later, have been quite happy to live.

Lastly, there are those who are going through $\rightarrow$ difficult phase and need treatment or care. Fogr instance, patients who have serious malnutrition problems, requiring the insertion of a feeding tub?. Where is the dividing line between treatment a $\overrightarrow{\mathrm{eg}}$ care given simply to sustain life?

\section{(B) THE ETHICS AND NUTRITION GROUP}

The experiment conducted at the Bordeax University Hospital was concerned originally wian the specific problem of providing nourishment $\frac{\circ}{00}$ patients unable to feed themselves or to express $\frac{0}{10}$ any valid way their consent to treatment.

In the case of some elderly patients, no family member or legal "guarantor" came forward and doctors therefore knew nothing about the patients' past which could help them understand the contert of their lives and take appropriate decisions regarsing treatment.

It is in instances such as these that the ethigil aspect of the question is vital. In a traditional medical relationship, doctors deal with illness or illnesses in the context in which the patient presents them.

The simple fact that a patient has come to see 度s doctor proves that there is a demand on his part for treatment. The doctor tries to respond by requirifg the patient to follow the treatment he recommends.

In the case of the elderly in question, however, tho demand is expressed (or too many demands ate made, which amounts to the same thing) and it is up to the doctor and the nursing team to decipher aff interpret the patient's personality and case histơny before reaching a decision.

We noted in some cases that the nursing tea who were very much involved in and committed the care and wellbeing of the patients, questionged, sometimes with justification, the course of treatment decided on.

A multidisciplinary group was therefore created, 
consisting of a medical team (doctors, nurses and nursing auxiliaries) and people from outside the hospital (a legal expert, a minister, a priest and patients' families). At each group meeting there were between 12 and 20 participants.

The work of the group consisted in drawing up an appraisal chart (see below) showing those parameters which could be relevant to a patient's situation at any given time, although we were all well aware that medical ethics is not a subject that can be readily broken down into a simple set of equations.

The group's most important contribution was unquestionably to the decision-making process. Although decisions were ultimately made by the doctor, they were considered in relation to the different reactions of group members to each individual case.

Thus, gradually, cases discussed at monthly meetings involved matters much more complex than the need for feeding tubes. The cases studied were all patients in the geriatric department of the hospital, but ages ranged from 65 to 95 , since the main problem we were looking at was not the age of their arteries but their mental and communicative capacities.

The next step for the group, and certainly the most difficult, will be to establish a protocol with the courts in order to give group discussions a legitimacy which they do not at present have.

It is perfectly reasonable to suggest that these well considered and carefully debated decisions, reached by a group of people who are involved at first-hand in the matter, are more relevant and better adapted to individual patients' needs than decisions by guardians who, in certain cases, are simply representing institutions.

Of course, if such an arrangement were successfully made, the doctor would still remain the sole decision-maker and would be in no way relieved of his responsibilities in this matter; but the group would constitute a guardian adapted specifically to the person concerned, a factor which is cruelly lacking in our legal system as it stands at present.

\section{Conclusion}

French law includes many measures which provide protection for the individual, but this protection is rigid and impersonal and in fact helps us very little in the problems with which we are faced when dealing with the elderly infirm.

From the ethical point of view, established concepts are better adapted and may assist carers, but medical ethics does not lend itself to logical solutions in this way and no solution can be pre-established.

The responsibility of the doctors is very important, and is often challenged, both at an individual level and as public sector health care providers.

But are we not burdening them sometimes with too many decisions ? The acceptance of death and aging is a problem that concerns society as a whole, and each of us as individuals. Our treatment of the elderly anticipates our own fate.

For this reason, attempts to consider these matters and take decisions collectively are of interest as they activate the responsibility of those involved, making them aware of the difficulties encountered when dealing with real-life situations.

To sum up, it is quite striking to see how, in society today, more and more disputes arise between individuals and the authorities.

One role that has devolved to those who care for the elderly is that of defending their patients' right to be individuals deserving of respect. In order to do this, the carers must fight against the rationalisation which is constantly eroding free will in everyday decisions, not at a formal level perhaps, but nevertheless, at an unconscious level.

\section{Preliminary notions for an ethical appraisal chart on patients being fed via gastrostomy}

Aim: to establish a set of parameters which will give an objective picture of a patient's situation at a given time

\section{Method:}

1 ) determine parameters:

- level of consciousness

- existence of any depressive signs

- short-term and medium-term prognosis

- family $->$ guardian

$\rightarrow$ team of carers

$\rightarrow$ home background

- life history, experience

- extent of participation in treatment

- age

- pain experienced, type of illness

2) Evaluation of findings, with coefficients attributed to factors of differing importance, established retrospectively

3) Future applications

Sophie Gromb is a Doctor of Private Law, Doctor of Medicine, a Forensic Pathologist, an Expert Adviser to the Courts of Law, and Head of the Department of Legal Medicine and Medical Law at Bordeaux University Hospital, Pessac, France. The late Gerard Manciet was Professor of Medicine (with teaching responsibilities) in the Department of Geriatrics, Bordeaux Teaching Hospital, and at Xavier Arnozan Hospital, Pessac. Arnaud Descamps is a Doctor of Medicine in the Department of Geriatrics, Bordeaux Teaching Hospital and at Xavier Arnozan Hospital, Pessac.

\section{Bibliography}

Wetle TT. Ethical issues in long term care of the aged. Fournal of Geriatric Psychiatry 1985; 18: 63-73. 
Massip J. Le régime juridique civil de la personne âgée en France. Gérontologie et société 1991; 59: 12-19.

Alexander MP..Clinical determination of mental competence. Archives of Neurology. 1988; 45: 23-6.

Dorr Goold S, Arnold R, Siminoff L. Discussions about limiting treatment in geriatric clinics. Fournal of the American Geriatric Society 1993; 41: 277-81.

Anonymous [editorial]. Mental incapacity and medical treatment. Lancet 1993; 341: 1123-4.

Hauser J. La protection par l'incapacité des personnes âgées dépendantes. Revue de Droit Sanitaire et Social 199 28: 467-80.

Wanzer SH, Adelstein J, Cranford R et al. The physician's responsibility toward hopelessly ill patients. New Englar Fournal of Medicine 1989; 320, 13: 844-9, and 15: 955-9; Loewy EH. Treatment decisions in the mentally impaire雨 New England fournal of Medicine 1987; 317, 23: 1465-g Libow LS, Olson E, Neufeld R et al. Ethics rounds at the nursing home: an alternative to an ethics committe fournal of the American Geriatric Society 1992; 40: 95-7.

\section{News and notes}

\section{Obstetrics and gynaecology}

The 28th British Congress of Obstetrics and Gynaecology (BCOG) will take place from 30 June-3 July 1998 at the Harrogate International Centre, UK. Further information is available from the
BCOG Secretariat, Congress House, 65 West Drive, Cheam, Sutton, Surrey SM2 7NG, UK. Tel: +44(0)181661 0877. Fax: +44(0)181661 9036. 